\title{
A partial factors methodology for structural safety assessment in non-linear analysis
}

\author{
Paula M. R. P. Castro† \\ Faculty of Architecture, Porto University, Rua da Gólgota, Porto, Portugal \\ Raimundo M. Delgado and José M. A. César de Sá $¥$ \\ Faculty of Engineering, Porto University, Rua Dr. Roberto Frias, s/n, 4200-465 Porto, Portugal \\ (Received July 1, 2004, Accepted January 15, 2005)
}

\begin{abstract}
In the present structural codes the safety verification is based on a linear analysis of the structure and the satisfaction of ultimate and serviceability limit states, using a semi-probabilistic security format through the consideration of partial safety factors, which affect the action values and the characteristic values of the material properties. In this context, if a non-linear structural analysis is wanted a difficulty arises, because the global safety coefficient, which could be obtained in a straightforward way from the non-linear analysis, is not directly relatable to the different safety coefficient values usually used for the different materials, as is the case for reinforced concrete structures. The work here presented aims to overcome this difficulty by proposing a methodology that generalises the format of safety verification based on partial safety factors, well established in structural codes within the scope of linear analysis, for cases where non-linear analysis is needed. The methodology preserves the principal assumptions made in the codes as well as a reasonable simplicity in its use, including a realistic definition of the material properties and the structural behaviour, and it is based on the evaluation of a global safety coefficient. Some examples are presented aiming to clarify and synthesise all the options that were taken in the application of the proposed methodology, namely how to transpose the force distributions obtained with a non-linear analysis into design force distributions. One of the most important features of the proposed methodology, the ability for comparing the simplified procedures for second order effects evaluation prescribed in the structural codes, is also presented in a simple and systematic way. The potential of the methodology for the development and assessment of alternative and more accurate procedures to those already established in codes of practice, where non-linear effects must be considered, is also indicated.
\end{abstract}

Keywords: structural safety; non-linear analysis; safety factors; assessment of codes; safety verification; second order effects; reinforced concrete frames.

\section{Introduction}

A realistic description of the behaviour of structures should take into account their non-linear nature, especially when the consideration of second order effects or seismic design are involved. In

\footnotetext{
$\dagger$ Assistant Professor, E-mail: Paula.P.Castro@netcabo.pt

$\ddagger$ Professor, Corresponding Author, E-mail: rdelgado@fe.up.pt.

市 Associate Professor, E-mail: cesarsa@fe.up.pt
} 
the current practice of design, a complete non-linear analysis is usually avoided due to its cost and complexity and when it is considered it is carried out in very simplified ways, despite the fact that because of the rapid evolution of computer capacities some of the difficulties associated with nonlinear analyses are being overcome.

However, if for linear analysis the safety assessment is well established, for non-linear analysis there is not yet a consensus. Even the more recent codes, such as the concrete structures codes (EC2 2002 and MC90 1990), are not very clear in their recommendations. Underlying the design of a structure is the imposition of a certain safety and serviceability (Ferry-Borges 1962), that is, the adoption of certain risks associated with the uncertainties of the real behaviour of the structure and of the external actions (Ayyub 1987).

With the ever-increasing sophistication and complexity of constructions, more rigorous criteria for structural safety assessment have emerged. This is as true at "level 0", referring to the first safety verifications in which the uncertainties are taken into account by previously prescribed empirical safety factors, as at "level 4" (Pinto 1997, Veneziano 1976, Eibl 1991), in which a direct evaluation of collapse probability, associated with social and economical principles, is made. Nevertheless, any verification, from "level 2" to "level 4", involves a considerable number of variables and sophisticated analysis models, which are nowadays difficult to use in current structural design. The current codes (EC2 or MC90) have therefore adopted a "level 1" safety format, but with some recommendations for the use of non-linear analyses.

The technical and scientific communities nowadays commonly accept the methodology for the safety evaluation of structures with a linear behaviour, but the same cannot be said about the safety evaluation in non-linear regimes. Despite the fact that the more recent codes (EC2 and MC90) allow the use of non-linear analyses, they are not included in a coherent safety format, simply transposing, with minor changes, the recommendations used in linear regimes. Some recent studies have appeared aiming to correct these discrepancies or to propose new safety formats but there is still no general consensus regarding this issue.

In this work a new safety format is presented. It takes into account both the material and the geometrical non-linear behaviour of the structures, and makes it possible to establish a direct relationship between the results obtained with such an analysis and those normally used in structural design. In particular, it permits the conversion of the ultimate internal force values obtained by a non-linear analysis into design values.

Initially a brief resumé of the available safety formats in linear and non-linear regimes in the current codes is presented, and in the case of the non-linear regimes some of the recently proposed security formats are reviewed. Aiming to overcome the difficulties of those formats the bases for a new security format for non-linear regimes are defined. This proposal takes into account three basic requisites: simplicity, realistic definition of the material properties and, finally, the possibility of relating the linear and non-linear results obtained with different analyses. This format requires the definition of a global safety factor, which can be easily evaluated in the scope of non-linear analysis, and which measures the maximum capacity load of the structure, whereas the partial safety factors, defined in the structural codes, are maintained. With the proposed format it will be possible not only to proceed with the verification of previously designed structures but also with the final design of the structure from the results obtained with a non-linear computer code.

The significance of the global safety factor is substantiated in the examples presented, from a simple structure example submitted to various load cases, and the different phases of the method proposed for safety evaluation in structural design using the results of a non-linear analysis are 
illustrated and summarised. The different options taken in relation with the material properties and action combinations are also clarified.

Finally the ability of the proposed methodology for assessing the performance of different codes in the evaluation of second order effects is shown, through a comparison of the simplified procedures for second order effects evaluation prescribed in EC2, MC90 and the Portuguese code, in a simple and systematic way.

\section{Safety verification in the modern structural codes}

In the present structural codes the safety verification is made through the consideration of partial safety factors, that affect the action values and the characteristic values of the material properties, and the satisfaction of certain ultimate and serviceability limit states. In particular for the ultimate limit states (ULS) this verification is made assuring that for each section:

$$
S_{d} \leq R_{d}
$$

where $S_{d}$ are the action design values and $R_{d}$ are the internal resistant forces or carrying capacities.

To obtain the design values of the acting forces on the structure, the characteristic values of the actions must be defined and the corresponding action combinations established. In these combinations the characteristic values of the actions are affected by partial safety factors $\left(\gamma_{f}\right)$ in order to take into account the uncertainties of the analysis model and the possibility of unfavourable deviations of the action values from their representative values (CEB-FIP 1988). These partial safety factors are usually represented by the symbols $\gamma_{G}$ and $\gamma_{Q}$, for permanent and variable actions, respectively.

For the ultimate limit states the fundamental combination of actions takes the well-known form:

$$
S_{d}=\sum_{i=1}^{m} \gamma_{G_{i}} G_{k_{i}}+\gamma_{Q}\left[Q_{k}+\sum_{i=1}^{n} \Psi_{0 j} Q_{k_{j}}\right]
$$

where $G_{k}$ and $Q_{k}$ refer to the characteristic values of the actions (permanent and variable) and $\Psi_{0 j}$ is the coefficient which defines the combination weight value for a particular action.

The safety coefficients are intended to take into account the uncertainties associated with the analysis model and with the variation of intensity of the actions. They are usually defined in the structural codes for persistent and transient design situations, assuming, for the most common cases of building structures and for unfavourable effects, the consensual values of 1.5 for $\gamma_{Q}$ and the values of 1.5 or 1.35 for $\gamma_{G}$ depending on the code under consideration.

The evaluation of the design value of a section resisting force, $R_{d}$, is carried out adopting appropriate constitutive laws for the material, usually non-linear laws, in which the representative values of the strengths are reduced by coefficients $\gamma_{M}$, in order to take into account the uncertainties of the material properties.

In these procedures of safety verification the evaluation of the action effects is generally carried out considering a linear behaviour. The most recent codes, (EC2, MC90), give some hints for the consideration of the non-linear behaviour, although with a similar format to the one used for a linear regime and therefore not completely adequate for the more recent methodologies that involve more realistic analyses, mainly in near rupture domains. The EC2 refers vaguely that for the non-linear 
analysis of a structure an adequate non-linear behaviour and material characteristics which represent stiffness in a realistic way should be used. In the methodology proposed by MC90 a non-linear analysis may be carried out assuming mean or characteristic values of the material properties up to the level of design-yield stress in the reinforcing steel; after yield is attained in critical regions the design values should be used in all the structure.

The safety assessment in non-linear regimes has received the attention of several researchers, namely amongst the Comité Euro-International du Béton (CEB), attempting to invoke higher levels of safety by using statistical and probabilistic techniques, (Liu and Kiureghian 1989, Teigen, et al. 1991a, 1991b, Rajashekhar and Ellingwood 1995, Eibl and Shmidt-Hurtienne 1995, Zhang and Ellingwood 1996). These techniques of difficult practical application permit, nevertheless, the establishment and assessment of simpler procedures for practical application in the safety verification in non-linear analyses, (Eibl and Schmidt-Hurtienne 1995). The work here presented aims to generalize the format of safety verification based on partial safety factors, well established in structural codes in the scope of linear analysis, for cases where non-linear analysis is needed. The procedure is particularly useful for the design of structures made with more than one material with different material partial factors, as is the case in reinforced concrete structures, and it is hoped that it could provide the basis for more reliable and simple methods to be included in the codes.

\section{A format for safety verification in non-linear regimes}

The proposed format for safety verification aims to preserve the principal assumptions made in the codes as well as a reasonable simplicity in its use. The methodology includes the realistic definition of material properties and structural behaviour and it is based on the evaluation of a global safety coefficient. As shown herein, this global safety coefficient is also very useful for an easy comparison of different procedures in structural analysis and design.

\subsection{Material properties and action values}

The assessment of structural behaviour in non-linear regimes is very sensitive to the material constitutive laws and it is therefore essential to adopt realistic values for material properties. According to MC90 mean values may be adopted. However, as Levi (1995) states, those values are not well defined in the referred codes: they are omitted for reinforcing steel, and for concrete only a general conversion formula is given. Nevertheless in MC90 the possibility is given for using characteristic values for that purpose.

The adoption of different values (mean, characteristic or design) for both steel and concrete strength may affect non-linear analysis results significantly, as the structure behaviour will differ from case to case and therefore different ultimate configurations will be obtained. These differences become more perceivable when non-linear effects become important, that is, they increase with the hyperstaticity degree and with the sensitivity to second order effects, as is illustrated elsewhere (Castro 1998).

In this work, characteristic values for both materials were assumed, as they seem the most prudent option from the safety viewpoint and are closer to the assumptions of the present structural codes. Moreover, since in current design practice resisting forces are determined from characteristic values, the relationship between these values and the values obtained from non-linear analysis become 
clearer. However, for the material properties that mostly influence the deformation, namely the elasticity modulus at the origin and the maximal traction strength of the concrete, mean values were adopted as they are recommended by those structural codes. In order to take into account the longterm compressive strength and possible unfavourable effects of load application, the characteristic compressive strength of the concrete $f_{c k}$ is affected by the factor 0.85 , as adopted in most structural codes.

For the determination of the action effects it is necessary to establish not only their representative values, i.e., the characteristic value for the principal action and the reduced characteristic values for other actions, but also the way they are combined and the sequence of their application. Hence, the analyses are performed considering the fundamental combinations for the ultimate limit state, as in expression (2), and applying the various actions, in the following sequence:

1. Application of the permanent actions $G_{k}$.

2. Application of the principal action with its characteristic value $Q_{k}$ and of all the variable actions with their combination values $\Psi_{0} Q_{k}$.

3. Application of all previous actions simultaneously and with increasing values.

\subsection{Global safety factor}

In structural codes, as referred to above, the uncertainties and variations associated with analysis and design are taken into account by partial safety factors, $\gamma_{f}$ and $\gamma_{m}$, for each action and material. This procedure, devised for linear analysis, cannot be directly used when a non-linear approach is assumed. Nevertheless, as it is current practice in this type of analysis, it is possible to define a global safety coefficient $\gamma$ that augments the service value of the actions until failure.

This coefficient results from the partial safety factors adopted for the actions, $\gamma_{f}$, usually the same for all actions, and for the materials, $\gamma_{m}$, with different values for steel $\left(\gamma_{s}=1.15\right)$ and concrete $\left(\gamma_{c}=1.5\right)$, and could be interpreted as the product of two factors, one related to the actions $\gamma_{F}$ and another related to the materials $\gamma_{M}$, according to

$$
\gamma=\gamma_{F} \gamma_{M}
$$

Therefore, in reinforced concrete structures, in which the design of the critical sections has been dictated by the same action combination, the factor $\gamma_{M}$ will have a value close to 1.15 (the value used for steel) if the ULS has been reached mainly by yielding of the reinforcing steel, and a value close to 1.5 (the value used for the concrete) if reached mainly by concrete compression and almost independently of the amount of reinforcing steel. Between these two values others will exist that correspond to different relative roles that reinforcing steel and concrete play in failure, depending on the design forces at each section, making it difficult to assess the degree of security of a structure from the evaluation of the corresponding global safety factor. Moreover, according to the assumptions relating to the use of a global safety coefficient, for a structure to verify the safety conditions it would be necessary that:

$$
\gamma_{f} \gamma_{s} \leq \gamma \leq \gamma_{f} \gamma_{c}
$$

Assuming the same partial safety factor, $\gamma_{f}$, for all actions considered, a reinforced concrete structure would therefore be under-designed for a $\gamma$ value lower than $\gamma_{f} \gamma_{s}\left(1.725\right.$, if $\left.\gamma_{f}=1.5\right)$ and 
over-designed for a $\gamma$ value greater than $\gamma_{f} \gamma_{c}$ (2.25, if $\left.\gamma_{f}=1.5\right)$. However, a structure may present a global safety factor $\gamma$ within the limits referred to and, according to the rules of the particular structural code used, could be considered under-designed or over-designed.

\subsubsection{Illustrative example}

In order to illustrate the aspects referred to above, and to clarify the concepts involved, a simple application is presented. The chosen example is a reinforced concrete cantilever column submitted to axial and flexural forces and where only material non-linear effects are present, therefore neglecting second order effects.

If $M$ and $N$ are the effects of a particular action on the critical section, the column may be designed for the forces $M_{S d}=\gamma_{f} M$ and $N_{S d}=\gamma_{f} N$ and, according the adopted structural code, a corresponding reinforcing steel area is obtained.

Performing the analysis of the structure for increasing values of the action considered until failure the corresponding global safety factor $\gamma$ is obtained. Having in mind that the structure is isostatic, and consequently the material non-linearity does not affect the internal forces, and that the structure was designed precisely for this pair of forces, it is therefore possible to state that the global safety factor is dictated by the partial safety factors adopted in the design.

As the action partial safety factor is known, $\gamma_{f}$, it is possible to determine the partial safety factor, $\gamma_{m}$, resulting from the use of the two material partial safety factors, $\gamma_{s}$ and $\gamma_{c}$, involved in the section design, through:

$$
\gamma_{m}=\frac{\gamma}{\gamma_{f}}=\frac{\gamma}{\gamma_{F}}
$$

In these cases, in which the non-linear effects do not lead to redistribution of the forces due to material non-linearity or to an increase in the internal forces owing to second order effects, the forces at failure $S_{r}$, obtained by a non-linear analysis of the structure, can be related to design forces $S_{d}$ by:

$$
S_{d}=\frac{S_{r}}{\gamma} \gamma_{f}=\frac{S_{r}}{\gamma_{M}}
$$

In order to show how the material partial safety factors vary, the cantilever column has been designed, for different acting forces, according to the Portuguese Code REBAP (1983), although the methodology developed may be applied, obviously, to any other code. The partial safety factor for the actions is assumed to be $\gamma_{f}=1.5$, the same reinforcing steel area on both sides of the section is used, the effective depth is taken as 0.9 of the overall depth of the column section and in the nonlinear analysis the material properties are taken with their characteristic values.

In Fig. 1 the values obtained for the global safety coefficient $\gamma$, for different values of the nominal moment $\mu$ and of the nominal axial force $v$, are presented. In almost all sections the safety interval defined in Eq. (4) is respected, i.e., the values of the global safety factor $\gamma$ take values varying between 1.725 and 2.25 (the only exception being the values around $v=0.4$ in the curve $\mu=0.1$ that correspond to sections in which the concrete resists higher forces than those installed and where, therefore, $\gamma$ assumes higher values than 2.25). This confirms the fact that if a section presents a higher value for $\gamma$ it does not mean that it corresponds to a higher degree of safety or that it can withstand higher forces. As $\gamma_{f}$ is the same and equal to 1.5 for all sections, which in this case change between two sections, is the value of $\gamma_{m}$, reflecting the different relative role that is playing each of the materials in failure. 


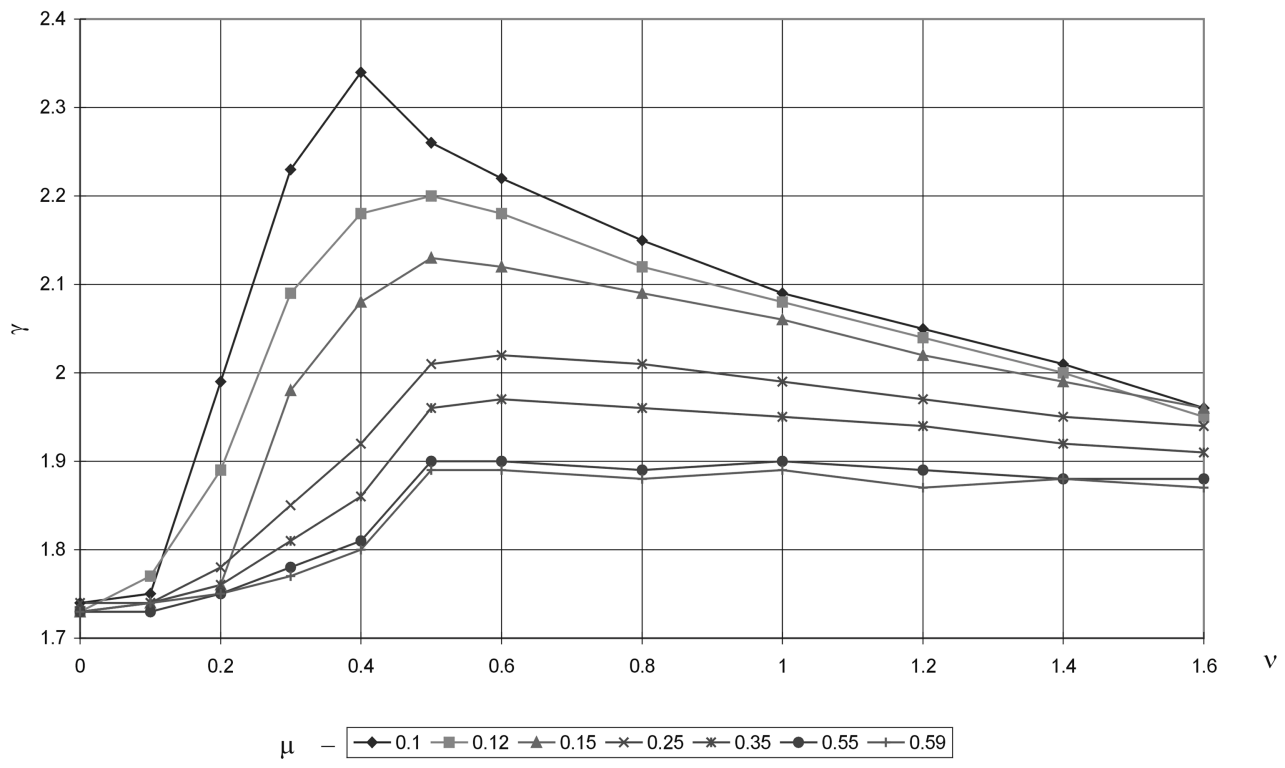

Fig. 1 Global safety factor $\gamma$

In the example shown in Fig. 2 the global safety factor is evaluated for an exact design and two other situations corresponding to an under-design and an over-design, with the area of the reinforcing steel varying approximately $30 \%$ relative to the exact design value. In the three cases, although there is a great variation in the amount of steel, the global safety coefficient lies within the "safety" interval defined in Eq. (4). This shows how this concept may be misleading in safety evaluation, and demonstrates that it is not possible to compare different structures by this global safety factor. The need to overcome this difficulty, while maintaining the partial safety factors strategy, is the starting point for the new methodology proposed here, aiming at the safety verification of existing structures, or in the design of new ones, taking into account their non linear behaviour and by assessing a global safety factor.

\subsection{Proposed methodology}

The safety assessment or the design of a structure based on a realistic analysis of its behaviour,

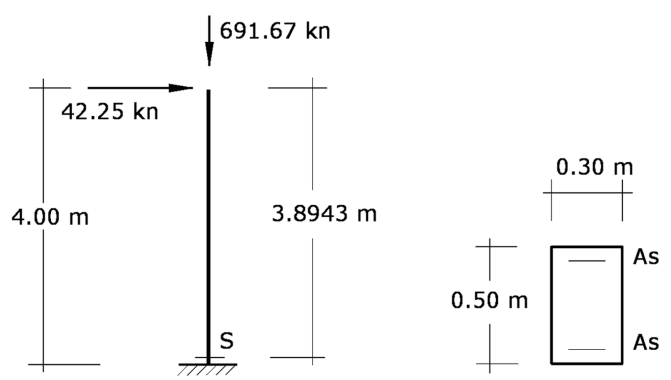

\begin{tabular}{|c|c|c|}
\hline & As (cm2) & $\gamma$ \\
\hline Correct design & 11.92 & 2.00 \\
\hline Over-designed & 15.5 & 2.23 \\
\hline Under-designed & 8.34 & 1.76 \\
\hline
\end{tabular}

Fig. $2 \gamma$ values for different design situations of a column 
considering the material and geometrical non-linear behaviour, involves a set of complexities whose resolution is not yet established in the available structural codes. In this context, the present work aims to contribute with a proposal that allows, in a simple way and from results obtained in a nonlinear analysis, either to proceed in the design of a structure, defining the most adequate reinforcing steel disposition to resist a certain action, or to verify the safety of a structure with a certain distribution of reinforcing steel and submitted to a certain action or combination of actions.

In the framework of this methodology the main idea consists in obtaining the design force values, in the same sense that they are considered in the structural codes, that is, involving the consideration of the partial safety factor of the action, but from a non-linear analysis. Hence, from a certain structure it is possible to obtain, using non-linear analysis, the distribution of forces $M_{r}$ and $N_{r}$ at the increment that precedes failure. If, as in the previous isostatic example, the force distributions would not be altered with the non-linear analysis, then the design forces could be obtained from $M_{r}$ and $N_{r}$, according to the expression:

$$
\begin{gathered}
M_{s d}=\frac{M_{r}}{\gamma} \gamma_{f} \\
M_{s d}=\frac{N_{r}}{\gamma} \gamma_{f}
\end{gathered}
$$

However, the material or geometrical non-linear effects lead to the fact that the design forces obtained in Eq. (7) do not coincide with the forces used in the section design, that is, the partial safety coefficient related with the materials, $\gamma_{M}$, is different from the one used in the section design. These new values $M_{s d}$ and $N_{s d}$ may now be used to assess the degree of security of the structure or as a basis for a new design.

From here we will denote by "reference reinforcing steel" and by "reference force distribution" the resultant values obtained by a non-linear analysis to which the partial safety factors (of the materials and of the actions) defined in the different structural codes (EC2, MC90 or REBAP) correspond exactly (or almost exactly).

\subsubsection{Determination of the reference reinforcing steel distribution to withstand a certain action combination}

In order to obtain an initial reinforcing steel distribution, $A_{s 0}$, an elastic analysis, for a given action combination, should be used and the corresponding amount of steel evaluated according to the structural code in use. The reference reinforcing steel distribution must be evaluated according the following steps, Fig. 3:

a) geometric and material non-linear analysis of the structure which gives the force distributions immediately before failure $S_{r_{i}}$ and the corresponding global safety coefficient $\gamma_{i}$;

b) determination of the design forces for the various sections $S_{d_{i}}$ by expressions Eq. (7);

c) new evaluation of the reinforcing steel area $A_{s_{i}}$ according to the forces obtained in b), using the provisions defined in the structural code, namely the partial safeti factors;

d) repetition of the procedures described in a) to c) with the change of the values $A_{s_{i}}$.

This iterative procedure stops when the reference solution for the reinforcing steel distribution is obtained, that is, when the reinforcing steel areas or the calculated forces in c) are, given a tolerance, approximately equal to the corresponding values in a). The described methodology is no 


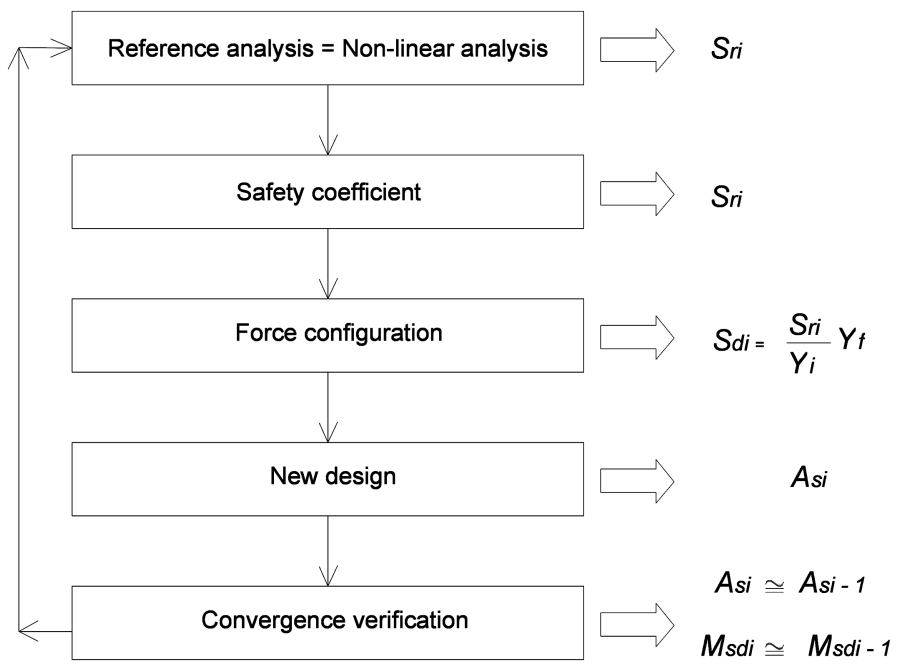

Fig. 3 Evaluation of the reference reinforcing steel

more than the design of the structure for an internal forces distribution proportional to the forces distribution obtained with a non-linear analysis, at the moment prior to failure, in which the sections used are sufficiently close to the ones now obtained.

The criterion for the assessment of the degree of approximation of the obtained solutions is based on the recommendations of MC90 when it defines the allowed approximation for the simplified methods in the evaluation of the ultimate limit state of buckling relative to the methods considered as rigorous second order analysis. Hence it is considered that if the bending moments $M_{s d_{i}}$ evaluated in the current iteration do not differ more than $10 \%$ from those determined in the previous iteration $M_{s d_{i-1}}$

$$
\left|\frac{M_{s d_{i}}-M_{s d_{i-1}}}{M_{s d_{i}}}\right| \leq 10 \%
$$

the configuration of the reinforcing steel obtained is taken as the reference reinforcing steel.

\subsubsection{Structural safety verification}

Taking into account the methodology developed in the previous section, it can be stated that a structure with a certain reinforcing steel distribution $A_{s}$ in accordance to a certain $M_{S d}$ distribution verifies the safety conditions if, for a given tolerance, the reinforcing steel area in each important section is similar to but greater than the necessary one:

$$
A_{s r} \cong A_{s}
$$

or, alternatively, given the moment distribution $M_{S d}$ from what $A_{s}$ was calculated:

$$
\frac{M_{r}}{\gamma} \gamma_{f} \cong M_{S d}
$$

In this expression for each section the bending moments $M_{r}$ correspond to the values obtained in 
the non-linear analysis for a reinforcing steel configuration $A_{s}$, and $A_{s r}$ is the reinforcing steel that corresponds to the design forces obtained from $M_{r}$ and $N_{r}$ by expression (7).

The criterion used to determine the degree of approximation of the obtained solutions using the bending moments may be extended to the reinforcing steel areas. Hence it is possible to state that a structure is safe if:

$$
\frac{A_{s r}-A_{s}}{A_{s r}} \leq 10 \%
$$

or

$$
\frac{\frac{M_{r} \gamma_{f}}{\gamma}-M_{S d}}{\frac{M_{r} \gamma_{f}}{\gamma}} \leq 10 \%
$$

The application of this criterion to very small values of forces and steel areas should be analysed for each case, as in practice the effective variation of the steel area may not be significant even if the defined tolerance has been exceeded, as will be shown in the next example.

\section{Application of the proposed methodology}

The first two examples aim to clarify and synthesise all the options that were taken in the application of the proposed methodology that will permit the transposition of the force distributions obtained with a non-linear analysis into design force distributions. Hence from the force values obtained in those analyses it will be possible not only to proceed with a current design of a structure but also to verify the safety of an already designed structure. The third example demonstrates one of the most important features of the proposed methodology, and it is one of the multiple examples studied (Castro 1998), allowing the comparison of the different procedure codes for second order effects evaluation.

\subsection{General characterisation}

In the following examples a finite element model for reinforced concrete plane frames was utilised. The model includes the consideration of material and geometrical non-linear effects (Castro 1998). In order to establish a direct relationship between the results of the non-linear analysis and those obtained by the current design, the material constitutive laws were chosen so as to correspond to a realistic behaviour and to be similar to the ones adopted in the structural code in analysis. Therefore the following relationships, illustrated in Fig. 4, were adopted: for steel a stress-strain bilinear diagram with no hardening; for concrete a stress-strain parabolic diagram as proposed by MC90 or EC2. These diagrams are identical for steel and very close for concrete to those adopted by REBAP.

The reinforcing steel areas were obtained resorting to the code REBAP and in this design the axial force in the beams was neglected, as it is usually done in the current design.

\subsection{Material properties}

In 3.1 the adoption of characteristic values for material properties was justified and an exception was 
Concrete

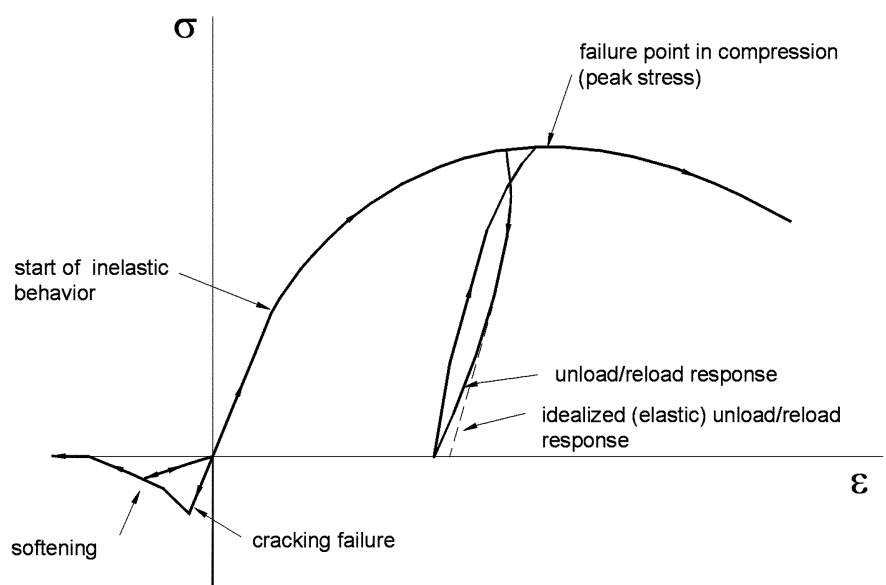

Steel

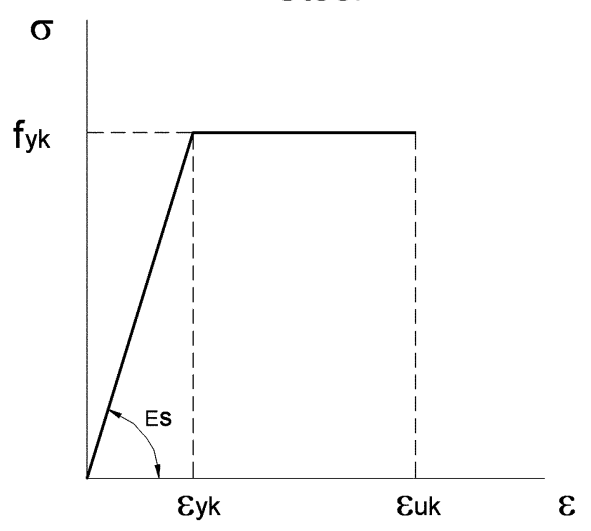

Fig. 4 General concrete model. Proposed steel model by REBAP and MC90

made for those properties that most influence deformation: the elastic modulus at the origin and the value of the maximum tensile strength of the concrete. The adopted properties for this example are the following:

- Concrete (C20/25-B25)

$$
E_{c m}=31.90 \times 10^{6} \mathrm{Gpa}, \varepsilon_{c 1}=2.20 \times 10^{-3}, f_{c k}=20.00 \times 10^{3} \mathrm{kpa}, \varepsilon_{c u}=3.50 \times 10^{-3}
$$

where $E_{c m}$ is the mean value of the tangent elastic modulus, $f_{c k}$ is the value of the characteristic strength in compression, $\varepsilon_{c 1}$ is the compressive strain that corresponds to the maximum stress and $\varepsilon_{c u}$ is the ultimate compressive strain.

- Reinforcing steel (A400)

$$
E_{s m}=200.00 \times 10^{6} \mathrm{kpa}, \varepsilon_{u k}=2.00 \times 10^{-3} ; \varepsilon_{y k}=10.00 \times 10^{-3}
$$

where $\varepsilon_{y k}$ is the characteristic value of the yield strain, $\varepsilon_{u k}$ is the characteristic value of the strain corresponding to the ultimate load and $E_{s m}$ the elasticity modulus.

\subsection{Action and action combinations}

In the examples studied the following actions were considered: permanent actions $G$, variable actions $Q$ and the wind $W$. These actions were combined according to rules defined by the structural code in use. To simplify the exposition only the combination that has the wind as the fundamental action will be analysed. The combination rule (2) may be re-written in this particular case as:

$$
S_{d}=\gamma(G+(W+0.7 Q))
$$


Since the path for loading is not indifferent to the scope for non-linear analysis, the following sequence of loads was considered:

1 - permanent actions with their characteristic value $G$,

2 - variable actions with their reduced value $0.7 Q$,

3 - wind action with its characteristic value $W$,

4 - increasing of all the applied actions, simultaneously, until structural failure.

Near failure load increment values of about $1 \%$ for the applied loads are used, in order to obtain a sufficiently accurate global safety factor.

\subsection{Two-storey frame}

The first example refers to a two-storey frame with two spans submitted to the loads represented in Fig. 5. Following to the two steps of the proposed methodology, initially a safety assessment of the designed structure was performed and then the distribution of the reinforcing steel was calculated, for this combination, by a non-linear analysis. The internal forces of the structure were obtained, by the non-linear computer code used, at the Gauss integration points of the finite elements.
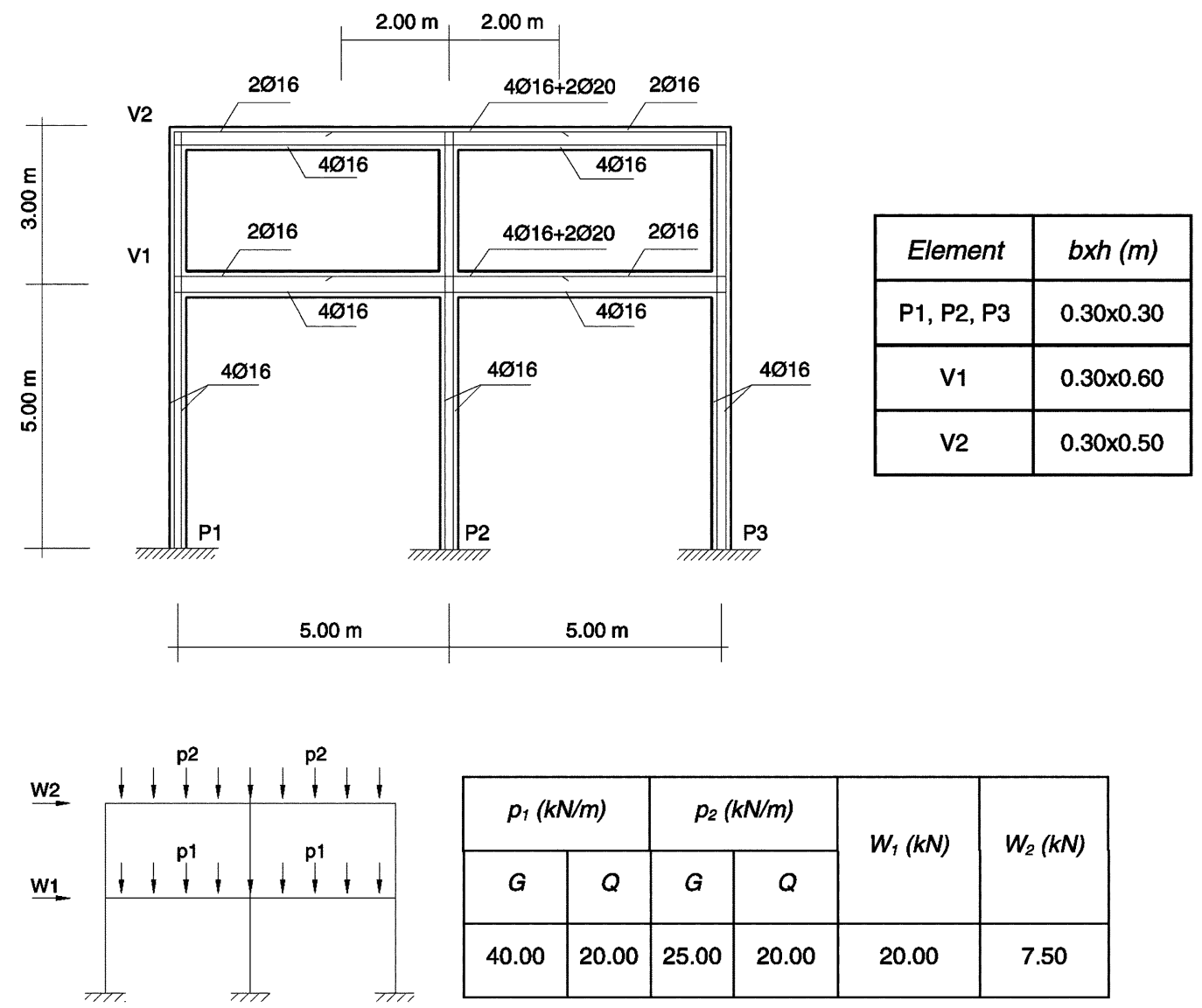

Fig. 5 Frame geometry and applied loads 


\subsubsection{Safety assessment}

At this point it is intended to verify if the structure characterised in 4.4 is safe. Therefore, and according to the proposed methodology in 3.3 , the following steps were taken:

1) Non-linear analysis of the structure giving the force distribution in the increment prior to failure, corresponding to a load factor of $\gamma=1.82$ (failure occurred for a load factor $\gamma=1.83$ ). In Fig. 6 the values of the bending moments $M_{r}$ are indicated at the sections used at the design level.

2) Determination of the design values according to the rupture values obtained in 1) and using expressions (7), Fig. 6 (b), in which the errors refer to those obtained at the initial design, expressions (11) e (12).

3) Safety assessment using expression Eq. (11), that is, assessment of the closeness between the following solutions: the proposed one, that corresponds to the reinforcing steel distribution represented in Fig. 5, and the one obtained by non-linear analysis, in which the reinforcing steel distribution was calculated from the forces obtained in 2). In this case it was verified that none of the sections needed more reinforcement, as in all of them the areas of reinforcing steel obtained by the linear analysis were greater than those obtained from the non-linear analysis. In Fig. 6(b) the relative errors between the proposed reinforcing steel areas and those obtained by that calculation are presented. The "over-design" of these areas range from $0.0 \%$ in a section of $V 1$ to $482.6 \%$ in a section of $\mathrm{P} 1$.

Hence it is possible to conclude that the structure, submitted to the load combination characterised in Fig. 5, verifies the safety conditions taking into account its non-linear behaviour and the specifications of the utilised structural code, REBAP.

\subsubsection{Reference reinforcing steel}

From the reinforcing steel configuration of Fig. 5 a configuration will be determined in order to optimise the structure. This configuration, designated "reference configuration", is obtained from the results of a non-linear analysis, involving an optimisation process. The steps that should be followed coincide with those indicated in 4.4.1 for safety verification and should be repeated as many times as necessary in order to obtain a good approximation between consecutive solutions so as to satisfy the condition stated in Eq. (8), i.e., the error should be less than $10 \%$.

After performing the first iteration it was verified that all sections were "over-designed" and in many cases the limit was exceeded by a considerable margin. Consequently the enunciated procedures have been repeated and the reinforcing steel distribution conveniently altered. These are again described for the second iteration:

1) Non-linear analysis of the structure whose reinforcing steel configuration is indicated in Fig. 6 (b); a force distribution has been obtained prior to rupture for a load factor $\gamma=1.71$, represented in Fig. 7 (a) for some sections that were determinant in the design of the various elements.

2) Determination of the design values, corresponding to the rupture values obtained in 1), from expression (7), Fig. 7 (b).

3) Re-design of the various sections according to REBAP and taking in account the design forces obtained in 2), Fig. 7 (b).

4) Evaluation of the degree of approximation of the reinforcing steel configuration inserted in the non-linear analysis 1) relative to the one obtained in 3). In this case it is possible to evaluate this approximation using the area values of the reinforcing steel or the bending moments, as 


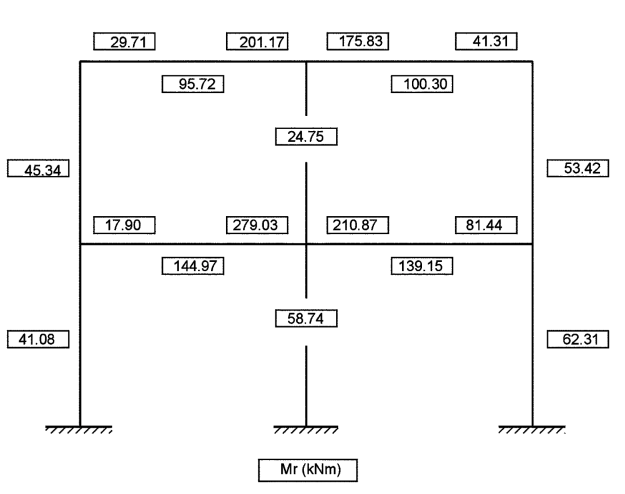

(a) Rupture bending moments obtained with the non-linear analysis

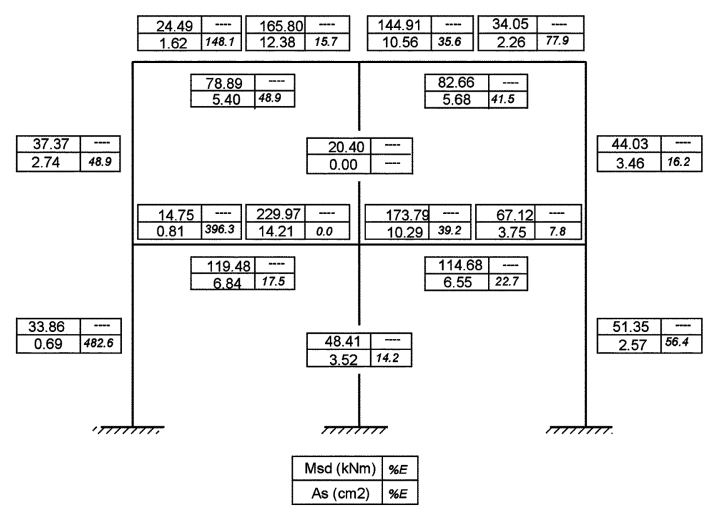

(b) Design bending moments and corresponding reinforcing steel areas

Fig. 6 Safety assessment of a structure according to the proposed methodology

they are both available. In order to clarify the analysis of the approximation involved, both values were determined.

As represented in Fig. 7, the maximum pre-defined limit of 10\%, relative to the previous configuration, has been exceeded in only one section where the absolute change in reinforcing steel is very low. In this and in similar cases of sections with very low forces, these changes are covered by the minimum values imposed by the structural codes of practice for the reinforcing steel areas in a section.

The reference reinforcing steel configuration was therefore obtained in only two iterations. In the various examples that were tested elsewhere (Castro 1998) it has been confirmed that convergence is, as expected, the more rapid the more adequate is the initial reinforcing steel distribution to the structure and to the applied loads. It will be shown next that, by starting with different steel reinforcing configurations, the iterative process may need different numbers of iterations to evaluate the reference reinforcing steel configuration which itself could be slightly different.

Finally one should mention the substantial amount of reduction in the reinforcing steel throughout the iterative process, as illustrated in the graph at Fig. 8 where the volume values of the reinforcing

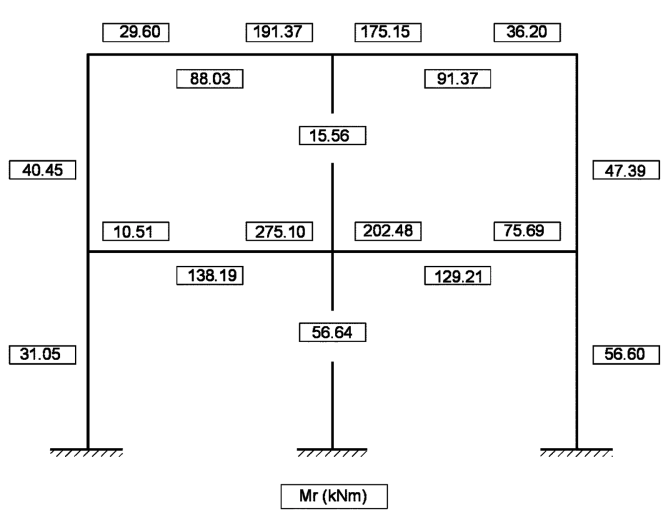

(a) Rupture moments obtained in the non-linear analysis

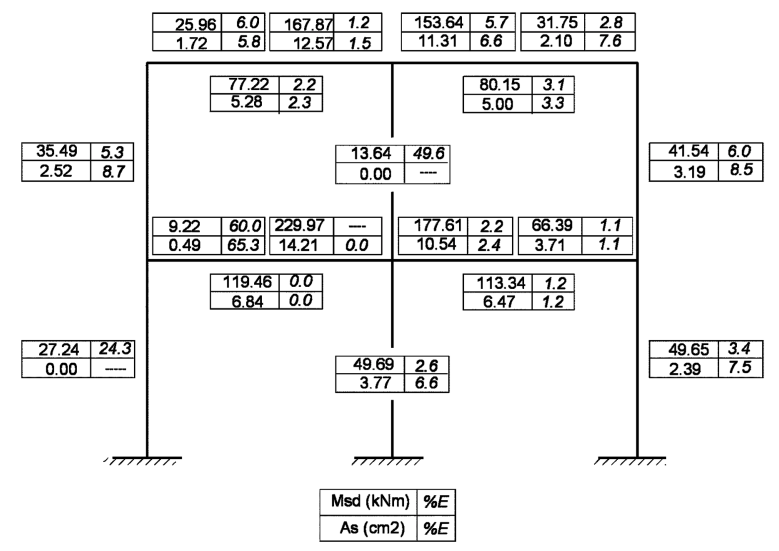

(b) Design moments and corresponding reinforcing steel areas

Fig. 7 Determination of a reference reinforcing steel distribution 


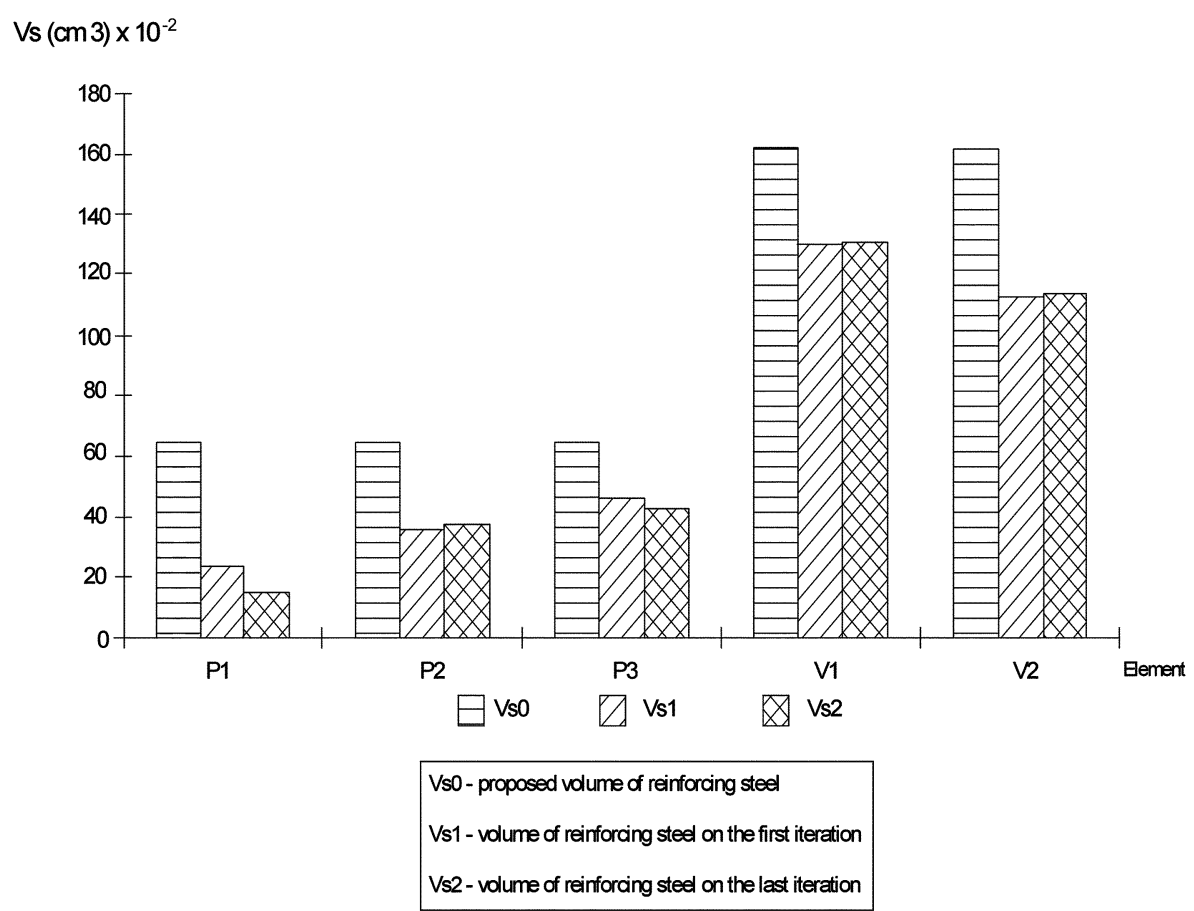

Fig. 8 Total values for the reinforcing steel volume throughout the iterative process to determine the reference configuration

steel for columns and beams are summarised, being $V_{s o}$ the proposed one $V_{s 1}$, the one obtained for the first iteration and $V_{s 2}$ the one obtained for the last iteration.

\subsubsection{Influence of the initial configurations on the reference reinforcing steel}

The reference reinforcing steel configuration that is obtained for a structure submitted to a certain load is not unique as it depends on the initial value $A_{s o}$ of the iterative process proposed in 3.2.1. The difference will be the more visible the bigger the differences between those initial values and the effects of the non-linear behaviour. In the particular case of the previously studied structure, big differences for distinct hypotheses of $A_{s o}$ are not expected to be obtained, due to its simplicity. Nevertheless, a new reference configuration was determined starting now from an initial reinforcing steel configuration $A_{s o}$ which is similar to that in Fig. 5, except in the columns where the area of the steel reinforcement was doubled. The iterative process, in this case, only converged after four iterations, which is not surprising due to the fact that $A_{s o}$ is more distant from the reference configuration.

The new reference configurations of the reinforcing steel and the corresponding forces are represented in Fig. 9. The value of the variation of the results obtained in the previous increment relative to this one is here also indicated for both the reinforcing steel and the bending forces.

Failure has occurred, as in the previous process, at the right end of beam $V 1$ for a load factor of $\gamma=1.72$. In Fig. 10 the two values of the reinforcing steel configurations obtained are represented, and some differences between the final results of the two hypotheses for $A_{s o}$ can be identified, with the biggest relative variations located near the intermediate node of the frame, attaining the value of 


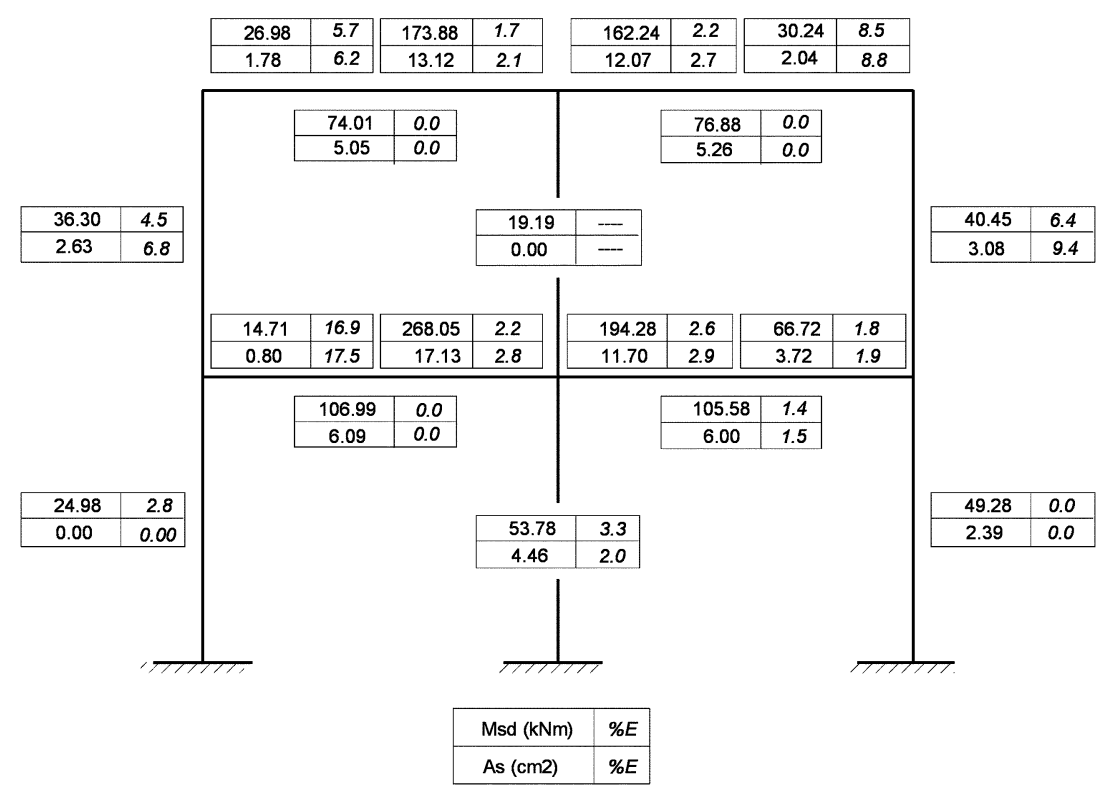

Fig. 9 Another reference configuration

$18.3 \%$ for column $P 2$, although in this location the absolute values for the steel area are small.

This example provides the conclusion that if it is required to compare different solutions using the concept of reference reinforcing steel, an important feature of the proposed methodology as has already been emphasised, is to consider an adequate value for $A_{s o}$, namely the actual reinforcing steel distribution that is required to be assessed.

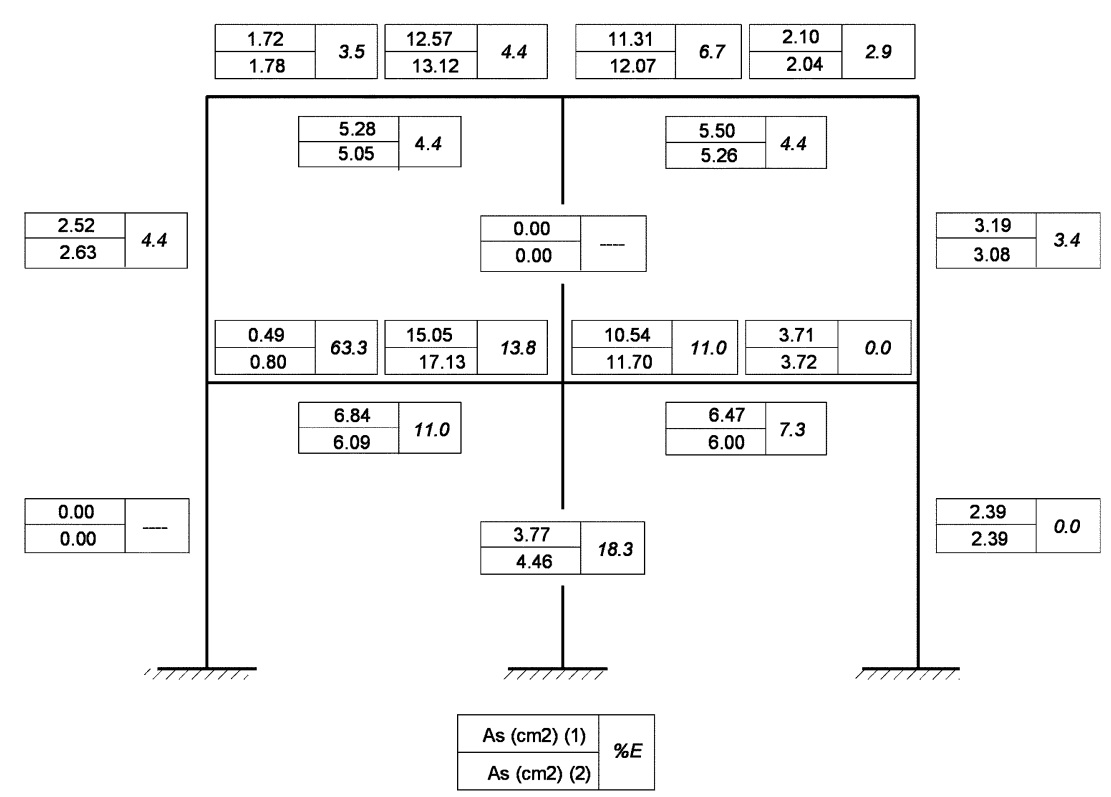

Fig. 10 Reference reinforcing steel obtained from different initial reinforcement steel distribution 


\subsection{Single-span and four-storey frame}

The second example refers to a single span, four-storey frame that is characterised in Fig. 11. As in the previous example, the reinforcement steel is determined in order to resist the same load combination and to verify the safety condition rules defined in the codes, using a non-linear analysis and the proposed methodology.

In this second example, some procedures currently adopted in the design were assumed in the various stages of application of the proposed methodology. In particular the criteria adopted for the reinforcing steel area distribution were the following: for the columns, the same areas were assumed for the two faces of the column cross-section and kept constant throughout their length; for the beams, a constant area was used for the soffit, corresponding to the maximum positive moment, and a constant area in the upper part of the beam corresponding to the minimum of the negative moments at the supports was considered; an extra reinforcement at the elements near the support with the maximum negative moment was added when needed. The minimum areas for reinforcing steel, according to EC2, were considered where it was necessary and are marked in the figures with $\min$. In these situations the moment values are not represented; otherwise the moment value that is in fact installed at the section is always represented.

Departing from the reinforcing steel distribution obtained from an elastic calculation of the bending moments, Fig. 12(a), the reinforcing steel distribution that verifies the safety conditions for

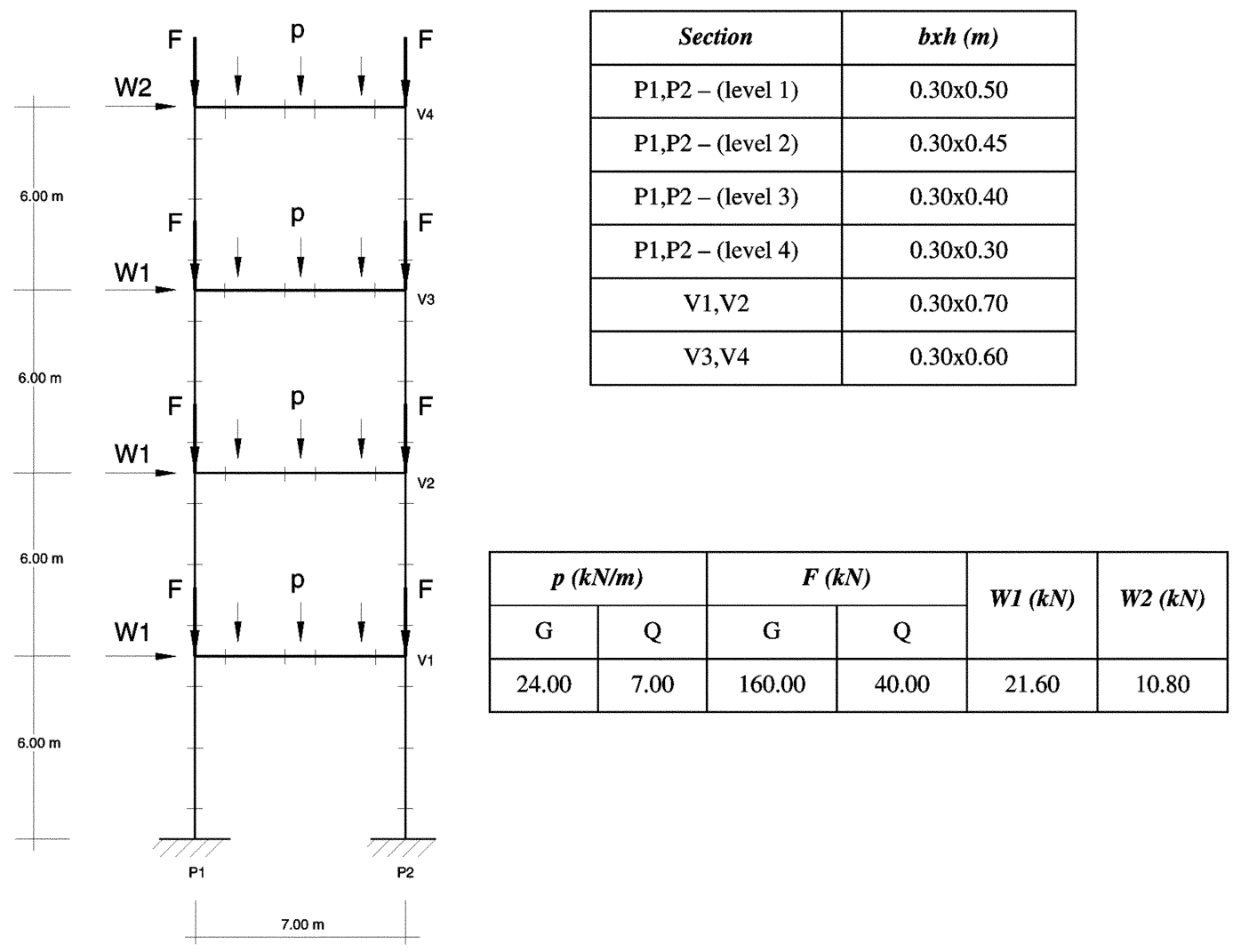

Fig. 11 Single-span, four-storey frame geometric characterisation and load definition 


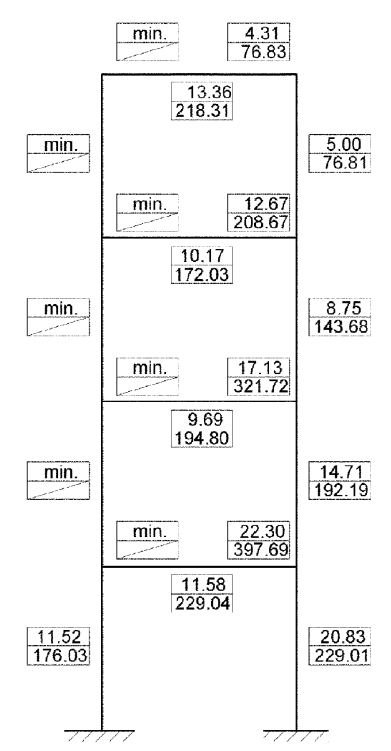

$\gamma=1.80$

(a)

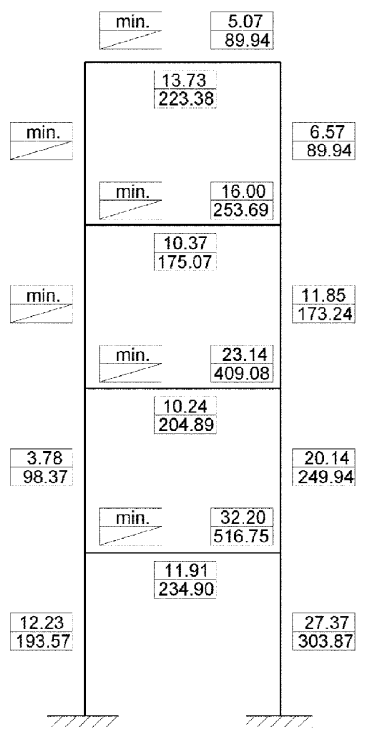

$\gamma=2.01$

(c)

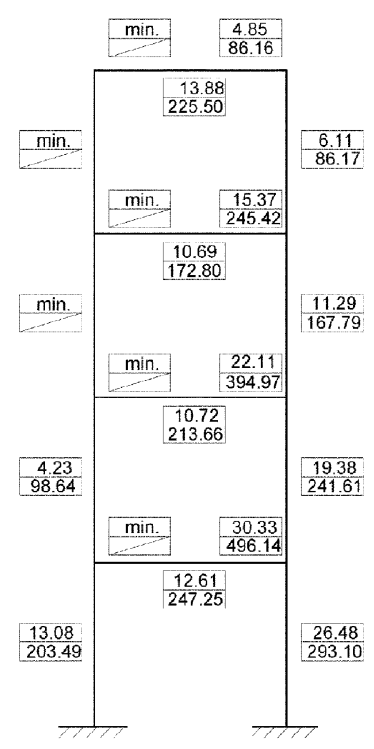

$\gamma=1.99$

(b)

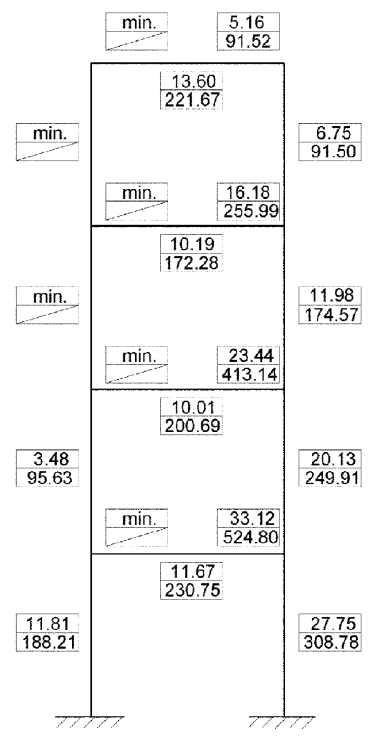

(d)

Fig. 12 Reinforcing steel areas and design moments for the different stages of the process

the force values is obtained by a non-linear calculation. In Figs. 12(b), (c) and (d), the reinforcing steel areas and respective design moments are represented for the different stages of the iterative 
process. It is recalled that the process is finished when the design moment values do not differ by more than $10 \%$ for two consecutive iterations. For each stage the load factor value $\gamma$ is also indicated.

As shown in Fig. 12, in the beginning of the iterative process, the load factor suffers a large variation from 1.80 to 1.99 and stabilises in the end of the process in the value of 2.01 . In the first iteration the lack of reinforcing steel resulting from the elastic calculation leads to a non-realistic reinforcement of column $P 1$ that is subsequently reduced in contrast to column $P 2$ that is reinforced in the latter stages.

These changes in the reinforcing steel areas lead, at the end of the iterative process, to an aggravation of the most significant initial values for $P 2$, reaching an increase of $26.9 \%$ in the second level, while only an increase of $2.5 \%$ is reached in the first level of $P 1$. The increase of $41.4 \%$ in the second level of $P 1$ is not significant as it only leads to an increase of $1.43 \mathrm{~cm}^{2}$ in the reinforcing steel area.

The forces in the beams undergo more significant changes at the ends near column $P 2$, resulting in beam $V 1$ in an increase of $24.2 \%$ for the design bending moment. At the left end the forces remain at values that correspond to minimum reinforcing steel areas.

Therefore the results shown in Fig. 12 show that:

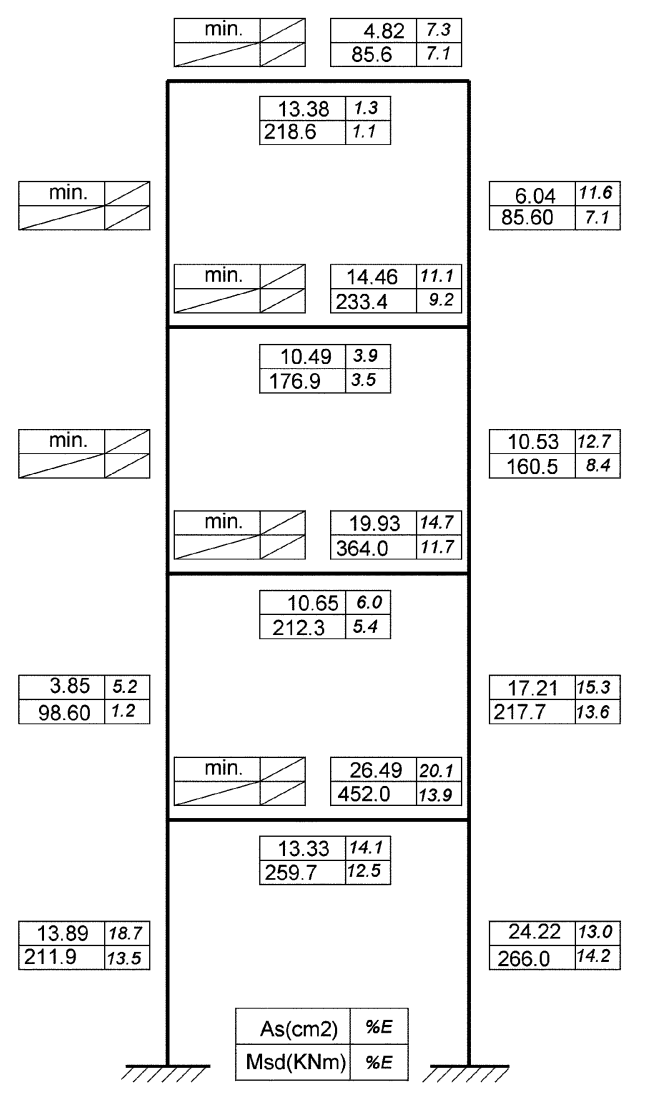

(a)

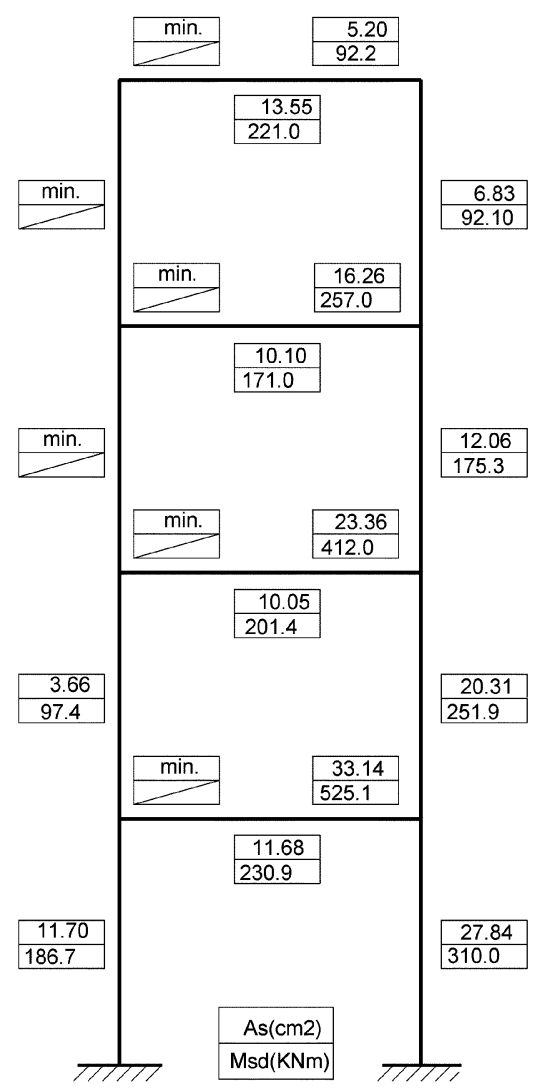

(b)

Fig. 13 Reinforcing steel and design moments a) MC90; b) Non-linear analysis-reference solution 
- the non-linear effects could be neglected at $P 1$, but not at $P 2$ as an increase of $25.8 \%$ in the moments at the base of the column was obtained;

- the non-linear effects are spread all over the structure showing that the different structural elements should not be studied in isolation, as is common in the codes of practice where the beams are usually neglected in the evaluation of the second order effects.

\subsection{Assessment of codes}

This third example illustrates how the proposed methodology could be used to compare different codes (MC90, EC2, REBAP) in the evaluation of second order effects, using the same structure of the previous example.

The initial reinforcing steel distribution for the iterative process was the one determined by each code or methodology by which it was assessed, and the errors were evaluated relative to the reference solution.

The results obtained with MC90 are presented in Fig. 13. It can be seen, in this example, that MC90 leads to large errors in the elements where the second order effects are more important, namely on column $P 2$ and on the right ends of the beams. It is also clear that it cannot reproduce the redistribution of the internal forces due to the non-linear behaviour of the material.

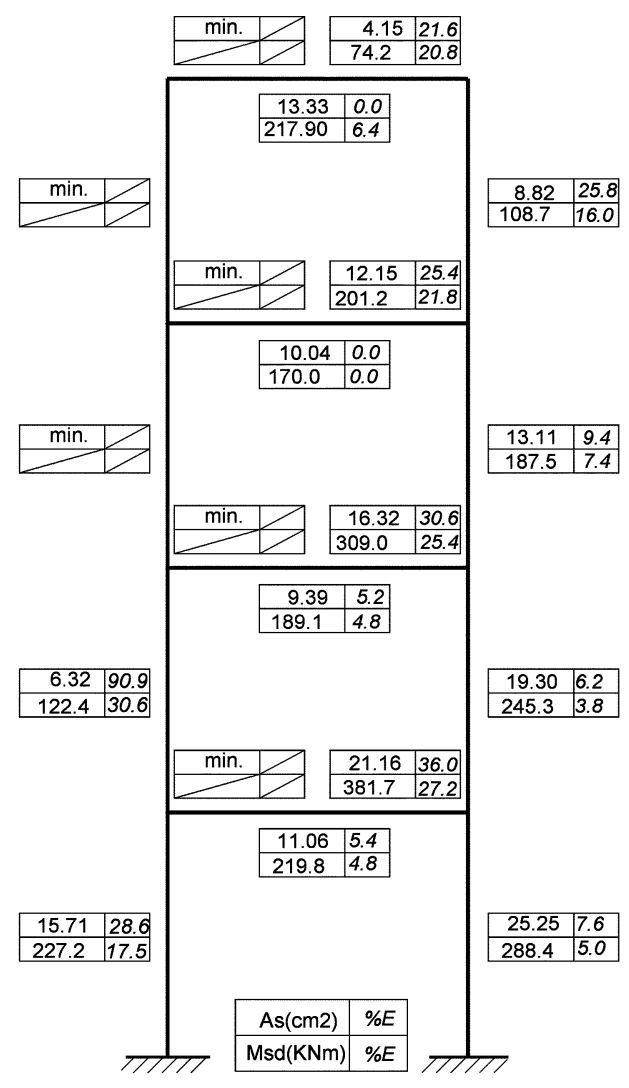

(a)

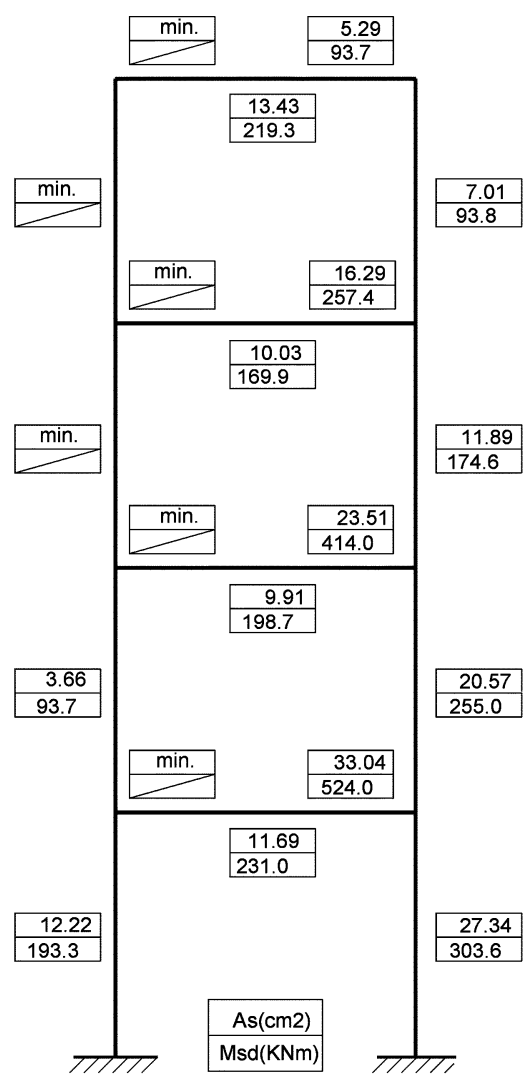

(b)

Fig. 14 Reinforcing steel and design moments a) REBAP; b) Non-linear analysis-reference solution 
Error at the soffit of the beams

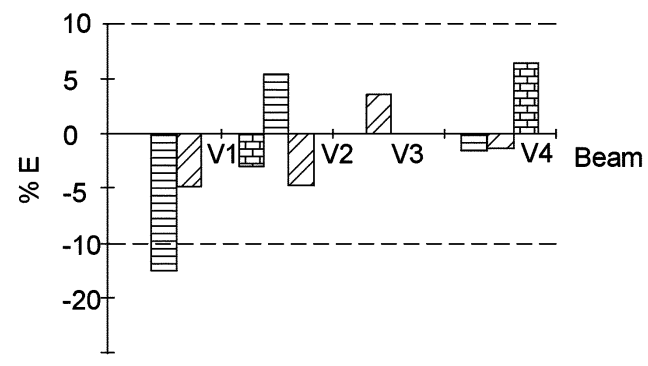

Error at column P1

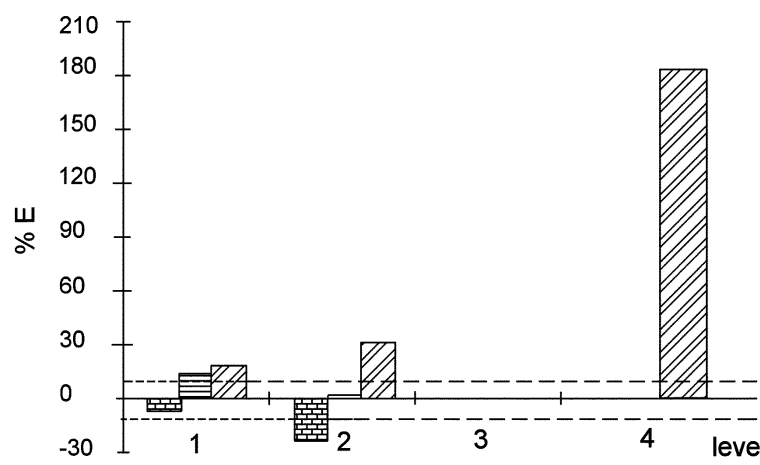

Error at the right end of the beams

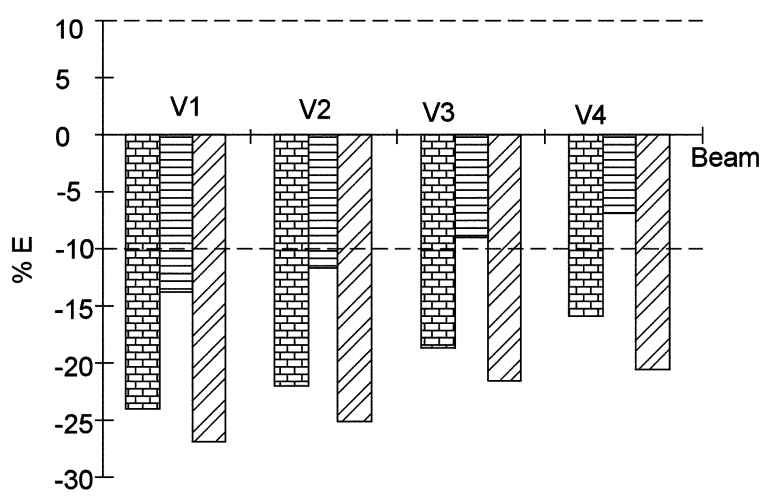

Error at column P2

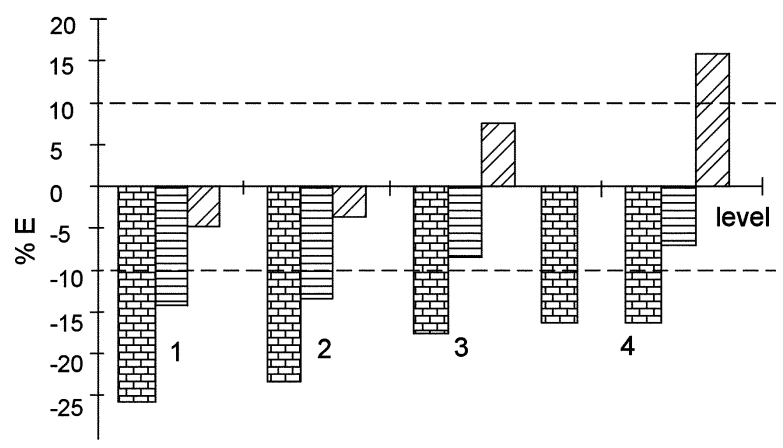

\section{国 $\mathrm{AE}$ 日 MC90ロ EC2}

Fig. 15 Comparison of reinforcement area obtained with the different codes relative to the reference solution

The results obtained with EC2 and REBAP are presented in Fig. 14. In this case the error in column $P 2$ is not so significant but column $P 1$ is clearly "overdesigned". Again the redistribution of the internal forces, namely the migration of the second order effects to the beam-ends is not captured.

In Fig. 15, the errors in the respective reference configurations are compared for the different codes, summarising the main comments made in the last two paragraphs. The $10 \%$ error limits are represented by a dashed line in all graphics. For column $P 1$ the results of the last two levels are not represented for MC90 as the steel reinforcement areas obtained were less than the minimum required by that code.

\section{Conclusions}

As far as could be observed, the three structural codes used for the design of the analysed structure lead to significant errors at some sections, meanwhile with MC90 better results were generally obtained. Moreover, it could be concluded that more reliable methods should be 
developed for taking into account second order effects, improving the very simplified procedures included in the actual codes. A new method based on the methodology described will be proposed in a next paper by the present authors for the evaluation of second order effects on reinforced concrete structures considering the non linear material behaviour.

The procedures proposed in the structural codes, based on partial safety factors for loads and materials, are essentially devoted to design based on linear analysis and are not suitable for the calculations where the non-linear effects are considered, either in the structural analysis or in the strength verification of the sections. This conclusion is underlined through the evidence that the consideration of a unique global safety factor is not sufficient for the verification of an accurate design. One can only state that beyond a "safety interval" the structure is underdesigned or overdesigned. But it was also shown that a certain structure could have a global safety factor within that interval and fail the safety conditions. In this work a new methodology was presented which allows the verification of the safety of a structure and to evaluate the more adequate reinforcing steel distribution, for a certain load combination, based on a non-linear analysis and maintaining the principal assumptions made in the current reinforced concrete frame design. The methodology includes the realistic definition of the material properties and of the structural behaviour and it is based on the evaluation of a global safety coefficient. The proposed methodology was illustrated with some examples, intended to detail the different steps and possibilities of its application as well as, and this is an important feature of this methodology, to demonstrate how simplified procedures, that is to say the ones established on structural codes, could be compared or assessed.

The ability of the methodology to compare the simplified procedures for second order effects evaluation, in an easy and systematic way, is demonstrated through an example, where EC2, MC90 and the Portuguese code are compared. It was concluded, from this particular structure, that the three structural codes lead to significant errors at some sections, and with MC90, better results were generally obtained.

Finally the enormous potential of the methodology for the development and assessment of alternative and more accurate procedures to those established in codes of practice can be asserted, particularly in the definition of reduced equivalent stiffness, for the structural elements, in order to take into account, in a realistic manner, the non-linear effects on the scope of linear analysis.

\section{References}

EC2, Eurocode 2 (2002), "Design of concrete structures- Part I: General rules and rules for buildings", European Committee for Standardization, Ref. No. prEN 1992-1-1.

MC90 - Comité Euro-International du Béton. (1990), CEB-Fip Model Code 1990, Bulletin dInformation, 204. Ferry-Borges, J. Castanheta, M. (1962), Structural safety. Laboratório Nacional de Engenharia Civil, Lisboa.

Ayyub, B. M., White G. J. (1987), "Reliability conditioned partial safety factors", J. Struct. Div., ASCE, 113(2), 279-294.

Pinto, A. (1997), "Earthquake performance of structures", Ph. D Thesis, Instituto Superior Técnico, Lisboa.

Veneziano, D. (1976), "Basic principles and methods of structural safety", Comité Euro-International du Béton, CEB, Bulletin dInformation 112.

Eibl, J. (1991), "Safety considerations for nonlinear analysis", Proc. IABSE Colloquium Struct. Conc. Stuttgart, 337-348.

CEB-FIP Comité Euro-International du Béton. (1988), "General principles on reliability for structures", Bulletin dInformation, 191.

Liu, P. L., Kiureghian A. D. (1989), "Finite element reliability methods for geometrically nonlinear stochastic 
structure", Report UCB/SEMM-89/05, Department of Civil Engineering, Division of Structural Mechanics, University of California, Berkeley.

Teigen, J. G., Frangopol, D. M. (1991a), "Sture S. Probabilistic FEM for nonlinear concrete structures - I Theory", J. Struct. Div., ASCE, 117(9), 2674-2689.

Teigen, J. G., Frangopol, D. M. (1991b), "Sture S. Probabilistic FEM for nonlinear concrete structures - II Applications", J. Struct. Div., ASCE, 117(9), 2690-2707.

Rajashekhar, M. R., Ellingwood, B. R. (1995), "Reliability of reinforced-concrete cylindrical shells", J. Struct. Div., ASCE, 121(2), 336-347.

Eibl, J, Schmidt-Hurtienne, B. (1995), "General outline of a new safety format, new developments in non-linear analysis methods", Comité Euro-International du Béton, CEB, Bulletin dInformation, 229, 33-48.

Zhang, J, Ellingwood, B. (1996), "SFEM for reliability with material nonlinearities", J. Struct. Div., ASCE, 122(6), 701-70.

Macchi, G. "Nonlinear analysis. the CEB approach, new developments in non-linear analysis methods", Comité Euro-International du Béton, CEB. 1995, Bulletin dInformation, 229, 7-11.

Levi, F., Marro, P., Viara, G. "Nonlinear analysis of beams and frames, new developments in non-linear analysis methods", Comité Euro-International du Béton, CEB 1995, Bulletin dInformation 227.

König, G., Fischer, J. (1995), "Model uncertainties of design equations for the shear capacity of concrete members without shear reinforcement", Model Uncertainties. Comité Euro-International du Béton, CEB, Bulletin dInformation, 224, 49-100.

König, G., Nguyem, T., Ahner, C. (1997), “Consistent safety format”, Comité Euro-International du Béton, CEB, Bulletin dInformation, 239, 1-16.

Castro, PMRP. (1998), "Models for buckling analysis of reinforced concrete framed structures", Ph. D Thesis (in portuguese), Faculdade de Engenharia da Universidade do Porto, Portugal.

REBAP - Regulamento de Estruturas de Betão Armado e Pré-esforçado (1983), Decreto-lei 349-C/83, Imprensa Nacional Casa da Moeda, Lisboa, Portugal. 